\title{
Nitrogen Isotope Fractionation During Archaeal Ammonia Oxidation: Coupled Estimates From Measurements of Residual Ammonium and Accumulated Nitrite
}

OPEN ACCESS

Edited by:

Laura E. Lehtovirta-Morley, University of East Anglia,

United Kingdom

Reviewed by:

Soo-Je Park,

Jeju National University, South Korea

Anne E. Taylor,

Oregon State University,

United States

Karen L. Casciotti,

Stanford University, United States

*Correspondence:

Wolfgang Wanek

wolfgang.wanek@univie.ac.at

${ }^{\dagger}$ Present address:

Maria Mooshammer,

Department of Environmental Science, Policy, and Management,

University of California, Berkeley,

Berkeley, CA, United States

Ricardo J. E. Alves,

Lawrence Berkeley National

Laboratory, Climate and Ecosystem

Sciences Division, Earth

and Environmental Sciences,

Berkeley, CA, United States

Barbara Bayer,

Department of Ecology, Evolution

and Marine Biology, University

of California, Santa Barbara,

Santa Barbara, CA, United States

Specialty section:

This article was submitted to Microbial Physiology and Metabolism,

a section of the journal

Frontiers in Microbiology

Received: 18 February 2020

Accepted: 29 June 2020

Published: 28 July 2020

\begin{abstract}
Maria Mooshammer ${ }^{1 t}$, Ricardo J. E. Alves ${ }^{2 t}$, Barbara Bayer't, Michael Melcher', Michaela Stieglmeier', Lara Jochum³, Simon K.-M. R. Rittmann', Margarete Watzka', Christa Schleper ${ }^{2}$, Gerhard J. Herndl ${ }^{2,4}$ and Wolfgang Wanek ${ }^{1 *}$
\end{abstract}

${ }^{1}$ Centre for Microbiology and Environmental Systems Science, University of Vienna, Vienna, Austria, ${ }^{2}$ Department of Functional and Evolutionary Ecology, University of Vienna, Vienna, Austria, ${ }^{3}$ LMU - Max von Pettenkofer Institute for Hygiene and Medical Microbiology, Ludwig Maximilian University of Munich, Munich, Germany, ${ }^{4}$ Department of Marine Microbiology and Biogeochemistry, Royal Netherlands Institute for Sea Research (NIOZ), Utrecht University, Utrecht, Netherlands

The naturally occurring nitrogen $(\mathrm{N})$ isotopes, ${ }^{15} \mathrm{~N}$ and ${ }^{14} \mathrm{~N}$, exhibit different reaction rates during many microbial $\mathrm{N}$ transformation processes, which results in $\mathrm{N}$ isotope fractionation. Such isotope effects are critical parameters for interpreting natural stable isotope abundances as proxies for biological process rates in the environment across scales. The kinetic isotope effect of ammonia oxidation (AO) to nitrite $\left(\mathrm{NO}_{2}{ }^{-}\right)$, performed by ammonia-oxidizing archaea $(\mathrm{AOA})$ and ammonia-oxidizing bacteria $(\mathrm{AOB})$, is generally ascribed to the enzyme ammonia monooxygenase (AMO), which catalyzes the first step in this process. However, the kinetic isotope effect of $\mathrm{AMO}$, or $\varepsilon_{A M O}$, has been typically determined based on isotope kinetics during product formation (cumulative product, $\mathrm{NO}_{2}{ }^{-}$) alone, which may have overestimated $\varepsilon_{A M O}$ due to possible accumulation of chemical intermediates and alternative sinks of ammonia/ammonium $\left(\mathrm{NH}_{3} / \mathrm{NH}_{4}{ }^{+}\right)$. Here, we analyzed ${ }^{15} \mathrm{~N}$ isotope fractionation during archaeal ammonia oxidation based on both isotopic changes in residual substrate $\left(\mathrm{RS}, \mathrm{NH}_{4}{ }^{+}\right.$) and cumulative product $\left(\mathrm{CP}, \mathrm{NO}_{2}^{-}\right)$pools in pure cultures of the soil strain Nitrososphaera viennensis EN76 and in highly enriched cultures of the marine strain Nitrosopumilus adriaticus NF5, under non-limiting substrate conditions. We obtained $\varepsilon_{A M O}$ values of 31.9-33.1\% for both strains based on $\mathrm{RS}\left(\delta^{15} \mathrm{NH}_{4}{ }^{+}\right)$and showed that estimates based on $\mathrm{CP}\left(\delta^{15} \mathrm{NO}_{2}{ }^{-}\right)$give larger isotope fractionation factors by $6-8 \%$. Complementary analyses showed that, at the end of the growth period, microbial biomass was ${ }^{15} \mathrm{~N}$ enriched $(10.1 \%)$, whereas nitrous oxide $\left(\mathrm{N}_{2} \mathrm{O}\right)$ was highly ${ }^{15} \mathrm{~N}$ depleted $(-38.1 \%)$ relative to the initial substrate. Although we did not determine the isotope effect of $\mathrm{NH}_{4}^{+}$ assimilation (biomass formation) and $\mathrm{N}_{2} \mathrm{O}$ production by $\mathrm{AOA}$, our results nevertheless show that the discrepancy between $\varepsilon_{A M O}$ estimates based on RS and CP might have derived from the incorporation of ${ }^{15} \mathrm{~N}$-enriched residual $\mathrm{NH}_{4}{ }^{+}$after $\mathrm{AMO}$ reaction into microbial biomass and that $\mathrm{N}_{2} \mathrm{O}$ production did not affect isotope fractionation estimates significantly.

Keywords: ammonia oxidation, nitrification, nitrous oxide, stable isotope fractionation, Thaumarchaeota 


\section{INTRODUCTION}

Knowledge of natural ${ }^{15} \mathrm{~N}$ abundances and of nitrogen $(\mathrm{N})$ isotope fractionation effects associated with key microbial $\mathrm{N}$ transformation processes has contributed greatly to our understanding of the marine $\mathrm{N}$ cycle (Casciotti and Buchwald, 2012; Buchwald and Casciotti, 2013) and of terrestrial gaseous $\mathrm{N}$ emissions (Houlton and Bai, 2009), namely atmospheric $\mathrm{N}_{2} \mathrm{O}$ sources and sinks (Yoshida and Toyoda, 2000), and biological $\mathrm{N}$ fixation (Vitousek et al., 2013). The oxidation of $\mathrm{NH}_{4}{ }^{+}$to $\mathrm{NO}_{2}{ }^{-}$-the first and rate-limiting step in nitrification-is a central process in the marine and terrestrial $\mathrm{N}$ cycles, as well as the major driver of a large $\mathrm{N}$ isotope effect that leads to formation of ${ }^{15} \mathrm{~N}$-depleted products such as $\mathrm{NO}, \mathrm{N}_{2} \mathrm{O}, \mathrm{NO}_{2}{ }^{-}$, and $\mathrm{NO}_{3}{ }^{-}$, while residual $\mathrm{NH}_{4}{ }^{+}$becomes ${ }^{15} \mathrm{~N}$-enriched during that process (Mariotti et al., 1981; Sigman and Casciotti, 2001). A detailed understanding of $\mathrm{N}$ isotope effects of the range of $\mathrm{N}$ transformation processes is thus critical for adequate biological interpretation of natural ${ }^{15} \mathrm{~N}$ isotope patterns in the environment (Casciotti, 2016).

Besides the recently discovered comammox bacteria (Daims et al., 2015; van Kessel et al., 2015), ammonia oxidation is catalyzed by both ammonia-oxidizing archaea (AOA) and ammonia-oxidizing bacteria (AOB), with different relative contributions across ecosystems and environmental conditions (Prosser and Nicol, 2012; Prosser et al., 2019). On a cellular level, ammonia oxidation is a multi-step process that comprises different enzymatic reactions and chemical equilibrium processes, which can all contribute to the $\mathrm{N}$ isotope fractionation effects inferred from extracellular $\mathrm{N}$ pools (Casciotti et al., 2003; Santoro and Casciotti, 2011). The isotopic fractionation effect $(\varepsilon)$ of ammonia oxidizers has been typically inferred based on changes in $\delta^{15} \mathrm{~N}$ of the cumulative product (CP) $\mathrm{NO}_{2}{ }^{-}\left(\varepsilon_{C P}\right)$, and attributed to the initial enzymatic step catalyzed by the ammonia monooxygenase (AMO) enzyme, defined as $\varepsilon_{A M O}$. However, $\varepsilon_{C P}$ estimates reflect the combined fractionation effects of the isotope equilibrium between $\mathrm{NH}_{4}{ }^{+}$ and $\mathrm{NH}_{3}\left[\mathrm{NH}_{3}\right.$, the proposed substrate for ammonia oxidation, is depleted in ${ }^{15} \mathrm{~N}$ relative to $\mathrm{NH}_{4}{ }^{+}$(Hermes et al., 1985)], the AMO-catalyzed reaction, and accumulation of several intermediates derived from subsequent enzymatic processes (Casciotti et al., 2003). For instance, $\varepsilon_{C P}$ estimates may be affected by the accumulation of essential intermediates, such as hydroxylamine $\left(\mathrm{NH}_{2} \mathrm{OH}\right)$ and by the production of gaseous $\mathrm{N}$ by-products (nitric oxide, $\mathrm{NO}$; and nitrous oxide, $\mathrm{N}_{2} \mathrm{O}$ ), which may represent further ${ }^{15} \mathrm{~N}$ fractionation steps. Consequently, this could result in a difference of kinetic isotope effect estimates derived from residual substrate (RS) and CP (Casciotti et al., 2003). Not only could these "leakage" processes alter CP-based estimates of $\varepsilon_{A M O}$, but their different contributions to ammonia utilization and to $\varepsilon_{C P}$ may also underlie the large differences observed in $\varepsilon_{A M O}$ between ammonia-oxidizing organisms (Mariotti et al., 1981; Yoshida, 1988; Casciotti et al., 2003; Santoro and Casciotti, 2011).

Estimates of isotope effects based on the change in $\delta^{15} \mathrm{NH}_{4}{ }^{+}$ $\left(\varepsilon_{R S}\right)$ can circumvent many of the expected biases associated with $\varepsilon_{C P}$, as they are not affected by the multiple subsequent equilibria, enzymatic transformations, and intermediate $\mathrm{N}$ pools, as discussed but not quantified previously (Casciotti et al., 2003; Santoro and Casciotti, 2011). However, to our knowledge, only one study has determined the isotope fractionation factors based on concurrent measurements of changes in isotopic composition of RS and CP of ammonia oxidation, namely in cultures of the AOB Nitrosomonas europaea (Mariotti et al., 1981). This study found no difference between $\varepsilon_{R S}$ and $\varepsilon_{C P}$, suggesting that ammonia oxidation can be effectively regarded as a "one-step process," where the AMO-catalyzed reaction constitutes the rate-limiting and sole isotope fractionation step. On the other hand, $\mathrm{AOB}$ and $\mathrm{AOA}$ seem to harbor fundamentally distinct ammonia oxidation pathways and exhibit different yields of gaseous $\mathrm{N}$ compounds per mole of $\mathrm{NH}_{4}{ }^{+}$ consumed (Walker et al., 2010; Kozlowski et al., 2016). Importantly, the enzyme hydroxylamine dehydrogenase (HAO), which performs the second step in ammonia oxidation of $\mathrm{AOB}$, has not been identified in $\mathrm{AOA}$, and thus it remains unclear how $\mathrm{NH}_{2} \mathrm{OH}$ is converted to $\mathrm{NO}_{2}{ }^{-}$in $\mathrm{AOA}$ (Walker et al., 2010; Kerou et al., 2016). Moreover, a recent study has provided evidence that the bacterial $\mathrm{HAO}$ oxidizes $\mathrm{NH}_{2} \mathrm{OH}$ to $\mathrm{NO}$ rather than to $\mathrm{NO}_{2}{ }^{-}$, as generally assumed, with the latter resulting from non-enzymatic oxidation of NO by oxygen (Caranto and Lancaster, 2017). Previous studies have shown that $\mathrm{NO}$ is also an essential intermediate in ammonia oxidation by AOA, as their growth and activity is highly sensitive to exposure to an NO scavenger (Shen et al., 2013; Kozlowski et al., 2016).

Here, we tested whether the kinetic isotope effect of archaeal ammonia oxidation based on $\mathrm{CP}\left(\delta^{15} \mathrm{NO}_{2}^{-}\right)$alone might be biased, by comparing the isotope fractionation factors inferred from both RS and CP pools. For this, we determined the kinetic isotope effects during growth of two phylogenetically and ecologically distinct AOA: the axenic strain Nitrososphaera viennensis EN76 (Stieglmeier et al., 2014a), isolated from soil, and the highly enriched marine strain Nitrosopumilus adriaticus NF5 (Bayer et al., 2016). This is also the first study of ${ }^{15} \mathrm{~N}$ isotope fractionation of ammonia oxidation by an AOA strain in pure culture. All previous studies of kinetic isotope effects of AOA have been performed with enrichment cultures with varying degrees of enrichment (Santoro and Casciotti, 2011; Nishizawa et al., 2016) and bacterial contaminants that may have contributed to the variation in isotope effects through consumption of and inputs to the same $\mathrm{N}$ pools.

\section{MATERIALS AND METHODS}

Pure cultures of $N$. viennensis EN76 were cultivated in freshwater medium and incubated at $37^{\circ} \mathrm{C}$, as described by Tourna et al. (2011). In a first experiment, quadruplicate cultures were supplemented with $1 \mathrm{mM} \mathrm{NH}_{4}^{+}$and $0.1 \mathrm{mM}$ pyruvate; in a second experiment, quadruplicate cultures were supplemented with $2 \mathrm{mM} \mathrm{NH}_{4}{ }^{+}$and $0.5 \mathrm{mM}$ pyruvate to generate higher cell biomass and sufficient $\mathrm{N}_{2} \mathrm{O}$ concentrations for isotopic analysis, in order to determine their potential effect on $\varepsilon_{A M O}$. Quadruplicate enrichment 
cultures of $N$. adriaticus NF5 were cultivated in Synthetic Crenarchaeota Medium (SCM) at $30^{\circ} \mathrm{C}$ as described by Bayer et al. (2016). The medium was supplemented with $1 \mathrm{mM}$ $\mathrm{NH}_{4}{ }^{+}$and $5 \%(\mathrm{v} / \mathrm{v})$ autoclaved seawater, which was sterilefiltered (0.22 $\mu \mathrm{m}$ GTTP, Millipore). Kanamycin at a final concentration of $100 \mu \mathrm{g} \mathrm{ml}^{-1}$ was used to inhibit bacterial contaminants. At the time of the experiment (January 2013), the enrichment level of strain NF5 was $\sim 95 \%$, as it contained a heterotrophic non-nitrifying/non-denitrifying contaminant of the alphaproteobacterial species Oceanicaulis alexandrii (Bayer et al., 2019).

Ammonia-oxidizing archaea growth was monitored by measuring nitrite production using the Griess method (Hood-Nowotny et al., 2010), coupled to $\mathrm{NH}_{4}{ }^{+}$consumption determined using the Berthelot method for $N$. viennensis cultures (Hood-Nowotny et al., 2010) and the o-Phthalaldehyde (OPA) method for N. adriaticus cultures (Goyal et al., 1988). $\delta^{15} \mathrm{NH}_{4}{ }^{+}$was quantified by microdiffusion (Sørensen and Jensen, 1991) with subsequent analysis on a continuous-flow isotope ratio mass spectrometer consisting of an elemental analyzer (EA1110, CE Instruments) coupled via a ConFlo III interface (Finnigan MAT, Thermo Fisher Scientific) to the isotope ratio mass spectrometer (IRMS; DeltaPLUS, Finnigan MAT, Thermo Fisher Scientific). $\delta^{15} \mathrm{NO}_{2}{ }^{-}$was determined based on the reduction of $\mathrm{NO}_{2}{ }^{-}$to $\mathrm{N}_{2} \mathrm{O}$ by azide under acidified conditions (Lachouani et al., 2010). Concentrations and isotopic ratios of $\mathrm{N}_{2} \mathrm{O}$ were determined using a purge-and-trap GC/IRMS system (PreCon - GasBench II headspace analyzer, Delta Advantage V IRMS; Thermo Fischer Scientific, Vienna, Austria). For $\mathrm{NH}_{4}{ }^{+}$and $\mathrm{NO}_{2}{ }^{-}$ isotope measurements, we included blanks, concentration standards, and isotope standards varying in natural ${ }^{15} \mathrm{~N}$ abundance together with the samples through the full microdiffusion and azide procedures to allow corrections for blank contribution, incomplete reaction, and procedural isotope fractionation (Lachouani et al., 2010). Nitrogen content and $\delta^{15} \mathrm{~N}$ signature of AOA biomass were determined by EA-IRMS as described above. $\delta^{15} \mathrm{~N}$ signatures $\left[\begin{array}{ll}\% & \text { vs. }\end{array}\right.$ AIR] were calculated relative to the ratio $\mathrm{R}\left({ }^{15} \mathrm{~N}:{ }^{14} \mathrm{~N}\right)$ of the atmospheric $\mathrm{N}_{2}$ standard (AIR), as $\delta^{15} \mathrm{~N}=\left(R_{\text {sample }} / R_{\text {standard }}\right.$ $-1) \times 1000$.

Isotope fractionation factors $(\varepsilon)$ were calculated based on the Rayleigh closed system isotope fractionation, based on changes in the isotopic compositions of RS (i.e., $\mathrm{NH}_{4}{ }^{+}$) and $\mathrm{CP}$ (i.e., $\mathrm{NO}_{2}{ }^{-}$) (Mariotti et al., 1981):

$$
\begin{aligned}
& 10^{3} \ln \frac{10^{-3} \delta_{R S}+1}{10^{-3} \delta_{S 0}+1}=\varepsilon \ln (f) \\
& \delta_{C P}-\delta_{S 0}=-\varepsilon f \frac{\ln (f)}{(1-f)},
\end{aligned}
$$

where $\delta_{S 0}$ is $\delta^{15} \mathrm{~N}$ of initial $\mathrm{NH}_{4}{ }^{+}, \delta_{R S}$ is $\delta^{15} \mathrm{NH}_{4}{ }^{+}, \delta_{C P}$ is $\delta^{15} \mathrm{NO}_{2}{ }^{-}$and $f$ is the fraction of the initial $\left[\mathrm{NH}_{4}{ }^{+}\right]$remaining in the culture. Plots of $10^{3} \frac{10^{-3} \delta_{R S}+1}{10^{-3} \delta_{S 0}+1}$ versus $\ln (f)$ and of $\delta_{C P}-\delta_{S 0}$ versus $f \frac{\ln (f)}{(1-f)}$ yield linear relations, with the slope representing the kinetic isotope effect based on the isotopic change in substrate $\left(\varepsilon_{R S}\right)$ and product $\left(\varepsilon_{A P}\right)$, respectively. Uncertainties of $\varepsilon$ are expressed as standard error of the slope. Differences in isotope fractionation effects between cultures were assessed by testing significant differences between their regression plots, using R (R Development Core Team, 2012).

\section{RESULTS AND DISCUSSION}

Based on the oxidation of $\mathrm{NH}_{3} / \mathrm{NH}_{4}{ }^{+}$to $\mathrm{NO}_{2}{ }^{-}-\mathrm{a}$ typical proxy for ammonia oxidizer growth, as it strongly correlates with growth rates (Stieglmeier et al., 2014a; Bayer et al., 2016)-all cultures showed growth curves typical for batch cultures of AOA, reaching stationary phase after 7 days for $N$. adriaticus, and after 3-4 days for $N$. viennensis cultures (Figures 1A-C). Nitrogen isotope fractionation was reflected in both the substrate (i.e., $\mathrm{NH}_{4}{ }^{+}$) and the product (i.e., $\mathrm{NO}_{2}^{-}$) of ammonia oxidation, and followed typical Rayleigh isotope fractionation kinetics for closed systems (Figures 1D-F): $\mathrm{NH}_{4}{ }^{+}$became increasingly ${ }^{15} \mathrm{~N}$-enriched with the fraction of $\mathrm{NH}_{4}^{+}$oxidized, while $\mathrm{NO}_{2}^{-}$was strongly ${ }^{15} \mathrm{~N}$-depleted after correction for $\mathrm{NO}_{2}{ }^{-}$deriving from the inoculum. With an increasing fraction of $\mathrm{NH}_{4}{ }^{+}$ oxidized, $\delta^{15} \mathrm{NO}_{2}{ }^{-}$converged toward the isotopic signature of the initial $\mathrm{NH}_{4}{ }^{+}$. Both $N$. adriaticus and $N$. viennensis (including cultures grown on 1 and $2 \mathrm{mM} \mathrm{NH}_{4}{ }^{+}$) exhibited ${ }^{15} \mathrm{~N}$ isotope fractionation factors based on substrate $\left(\varepsilon_{R S}\right)$ between 31.9 and $33.1 \%$, and based on product $\left(\varepsilon_{C P}\right)$ between 37.7 and $49.1 \%$ (Figures 2A-F). We found no significant difference between the isotope fractionation factors of the different AOA cultures studied here based on $\delta^{15} \mathrm{~N}$ evolution of the substrate $\left(\varepsilon_{R S}\right.$; comparison of slopes, $d f=2$, $F=0.519, p=0.598)$ or the product $\left(\varepsilon_{C P}\right.$; comparison of slopes, $d f=2, F=2.380, p=0.102)$. The $\mathrm{N}$ isotope fractionation factors based on $\delta^{15} \mathrm{NO}_{2}{ }^{-}\left(\varepsilon_{C P}\right)$ were larger than those based on $\delta^{15} \mathrm{NH}_{4}{ }^{+}\left(\varepsilon_{R S}\right)$ by $8.0,5.8$, and $5.9 \%$ for $N$. adriaticus, and for $N$. viennensis grown on $1 \mathrm{mM}$ or $2 \mathrm{mM}$ $\mathrm{NH}_{4}{ }^{+}$, respectively.

Nitrogen isotope fractionation has been studied in several AOB strains, but only in three marine and one thermophilic AOA enrichment cultures. These AOA enrichment cultures showed average $\mathrm{N}$ isotope fractionation factors between 22 and $25 \%$ at low substrate concentrations, and up to $32.0 \%$ at higher ammonium concentrations (Santoro and Casciotti, 2011; Nishizawa et al., 2016, measured via the isotopic composition of the product nitrite; see Table 1). These estimates are in the same range as the reported average isotope effects for different AOB strains, i.e., 1438\%0 (Delwiche and Steyn, 1970; Mariotti et al., 1981; Casciotti et al., 2003). ${ }^{15} \mathrm{~N}$ isotope fractionation factors of $N$. viennensis and $N$. adriaticus are in the upper range, or higher, than those previously reported for AOA, which might be due to the higher ammonia concentrations applied in our study (1-2 mM in our study vs. $200 \mu \mathrm{M}$ in Nishizawa et al., 2016; 10-75 $\mu \mathrm{M}$ in Santoro and Casciotti, 2011). Previous studies have indicated that higher initial ammonia concentrations lead to more stable 


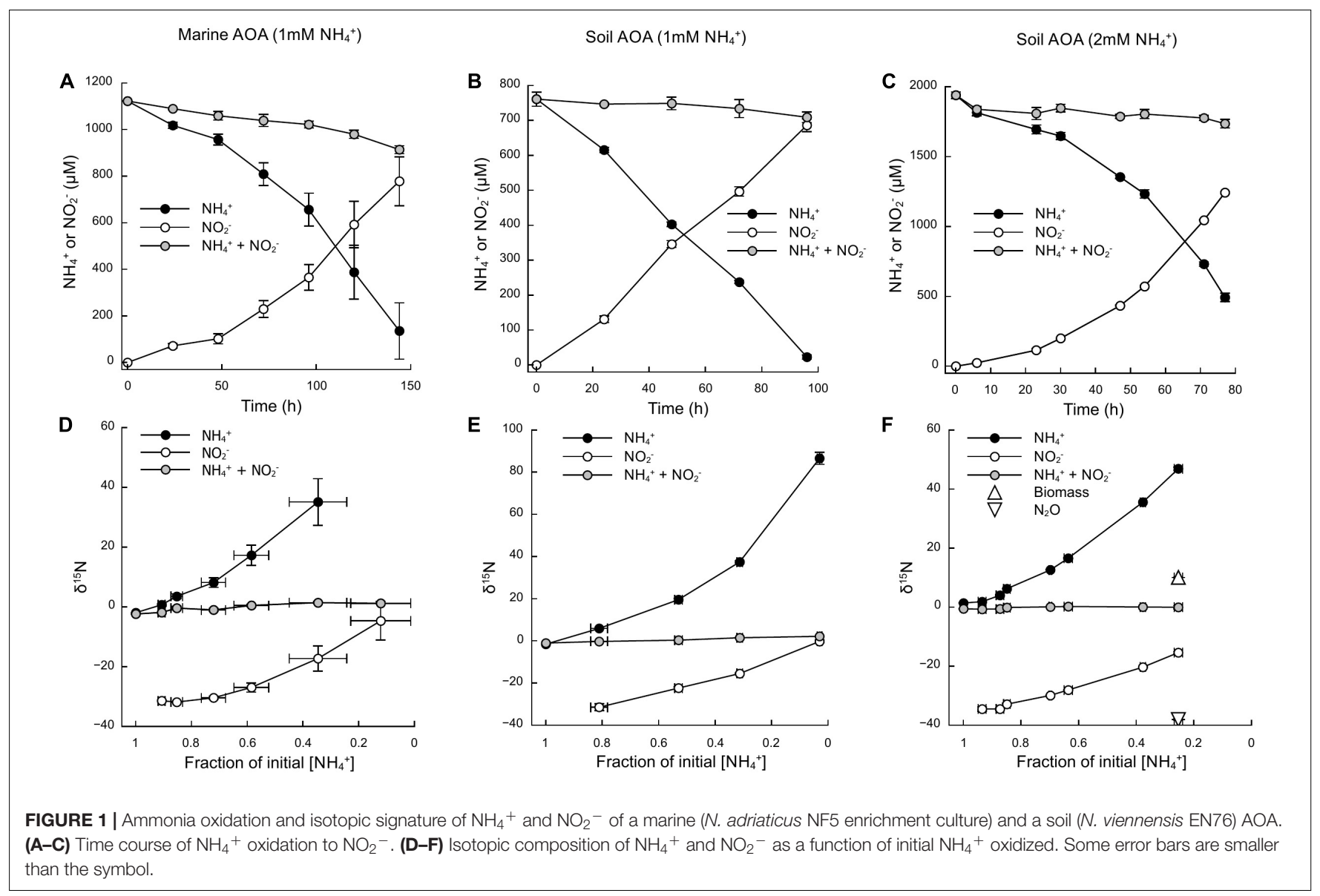

and higher ${ }^{15} \mathrm{~N}$ isotope fractionation (Casciotti et al., 2003; Santoro and Casciotti, 2011).

We also measured $\varepsilon_{A M O}$ based on changes in $\delta^{15} \mathrm{NH}_{4}{ }^{+}$ (i.e., the residual substrate) to both circumvent and assess potential biases associated with estimates based on $\delta^{15} \mathrm{NO}_{2}{ }^{-}$ (i.e., the cumulative product). It should be noted, however, that different apparent isotope effects in whole cells may also be observed in the $\mathrm{NH}_{4}{ }^{+}$pool, despite constant AMO enzymelevel isotope effects, depending, for example, on the balance between ammonia oxidation rates and ammonia diffusion across the S-layer (i.e., outermost cell envelope component in AOA) (Casciotti et al., 2003; Li et al., 2018). Published models of AOA and $\mathrm{AOB}$ metabolism favor the hypothesis of a (pseudo-)periplasmic location of the ammonia oxidation process (Arp and Stein, 2003; Walker et al., 2010; Simon and Klotz, 2013). However, $\mathrm{AOA}$ and $\mathrm{AOB}$ harbor very distinct $\mathrm{NH}_{3} / \mathrm{NH}_{4}{ }^{+}$transport systems (Offre et al., 2014), whose role in ammonia oxidation and contribution to observed differences in ${ }^{15} \mathrm{~N}$ isotope fractionation remain unclear (Arp and Stein, 2003). At low ammonia concentrations, ammonia oxidation rates are expected to become limited by $\mathrm{NH}_{4}{ }^{+}$ transport $/ \mathrm{NH}_{3}$ diffusion, resulting in the convergence of the isotope effect toward that of $\mathrm{NH}_{4}{ }^{+} / \mathrm{NH}_{3}$ equilibrium (if $\mathrm{NH}_{3}$ is mainly taken up by the cells) or $\mathrm{NH}_{4}{ }^{+} / \mathrm{NH}_{3}$ transport. The $\mathrm{NH}_{4}{ }^{+} / \mathrm{NH}_{3}$ equilibrium isotope effect has been estimated to be $19.2 \%$ in aqueous solution (Hermes et al., 1985), whereas secondary active ammonium (AMT) transporters, which are highly expressed in AOA (Carini et al., 2017), have been shown to exert isotope fractionation of around 13-15\% , due to deprotonation of $\mathrm{NH}_{4}{ }^{+}$during transport (Ariz et al., 2018). It is unlikely that ammonia oxidation has been limited by $\mathrm{NH}_{3}$ availability in our study, because of the high substrate concentrations used, which are well above the $K_{m}$ of the AMO of $N$. viennensis $\left(5.4 \mu \mathrm{M} \mathrm{NH} 3+\mathrm{NH}_{4}{ }^{+}\right.$; Kits et al., 2017) and that of the marine strain Nitrosopumilus maritimus strain SCM1 $\left(0.13 \mu \mathrm{M} \mathrm{NH} \mathrm{N}_{3}+\mathrm{NH}_{4}{ }^{+}\right.$; Martens-Habbena et al., 2009), which is closely related to $N$. adriaticus. Furthermore, Nishizawa et al. (2016) estimated that, when $\mathrm{NH}_{3}$ concentrations in the pseudo-periplasm are lower than in the medium under laboratory conditions, cell-specific $\mathrm{NH}_{3}$ diffusion rates into the pseudo-periplasm are higher than cell-specific ammonia oxidation rates. It has also been proposed that the charged S-layer proteins of AOA enhance the diffusion of charged solutes, such as $\mathrm{NH}_{4}{ }^{+}$, which concentrates $\mathrm{NH}_{4}{ }^{+}$in the pseudo-periplasmic space near the active site of the AMO ( $\mathrm{Li}$ et al., 2018), where then the equilibrium reaction between $\mathrm{NH}_{4}{ }^{+}$and $\mathrm{NH}_{3}$ is relatively fast and considered not to be rate-limiting.

Even if ammonia oxidation was not limited by periplasmatic $\mathrm{NH}_{3}$ availability, the apparent isotope effect of the AMO can 
Marine AOA (1 $\left.\mathrm{mM} \mathrm{NH}_{4}^{+}\right)$
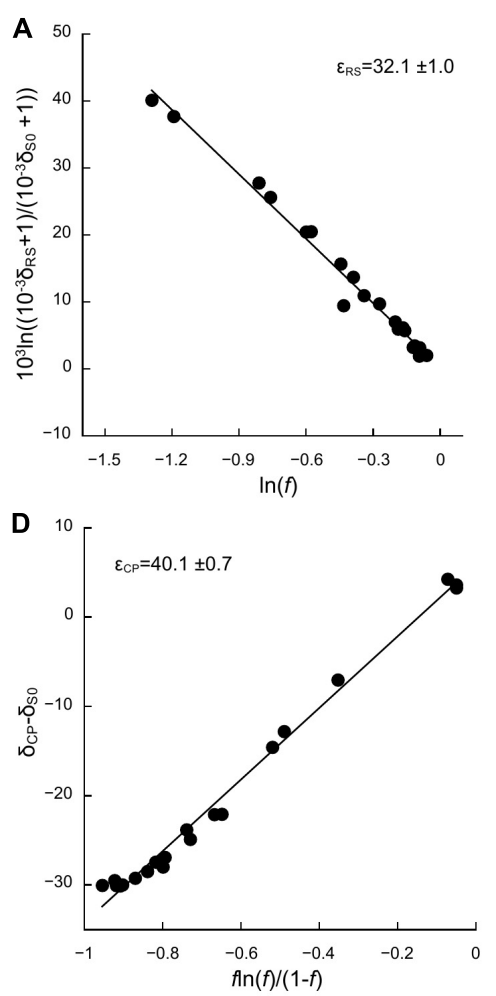

Soil AOA $\left(1 \mathrm{mM} \mathrm{NH}_{4}^{+}\right)$

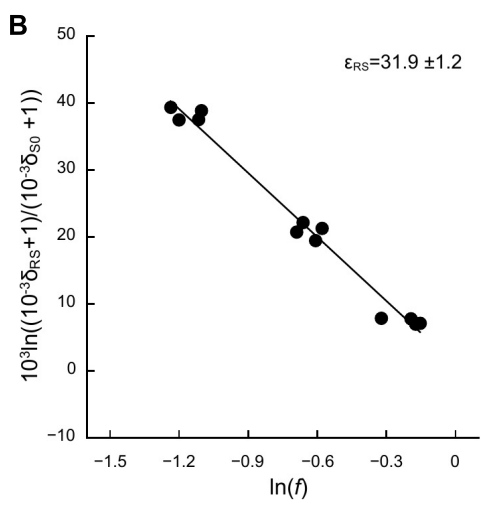

E

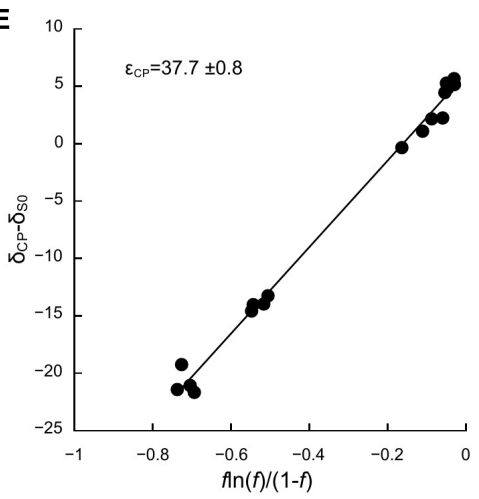

Soil AOA $\left(2 \mathrm{mM} \mathrm{NH}_{4}^{+}\right)$

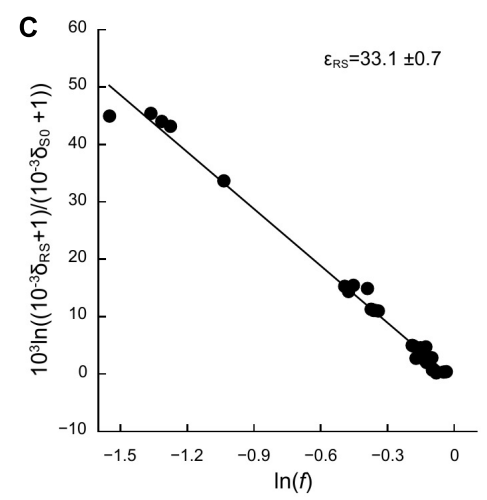

$\mathbf{F}$

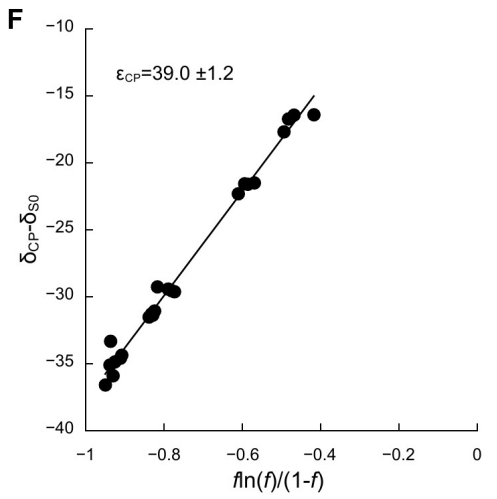

FIGURE 2 | Kinetic isotope effects of the marine AOA N. adriaticus and the soil AOA N. viennensis. Isotope fractionation factors ( $\varepsilon_{R S}$ and $\left.\varepsilon_{C P}\right)$ were calculated based on changes in (A-C) $\delta^{15} \mathrm{~N}-\mathrm{NH}_{4}{ }^{+}\left(\delta_{R S}\right)$ and (D-F) $\delta^{15} \mathrm{~N}-\mathrm{NO}_{2}{ }^{-}\left(\delta_{C P}\right)$, using linear regressions of $10^{3} \frac{10^{-3} \delta_{R S}+1}{10^{-3} \delta_{S O}+1}$ versus In $(f)$ and $\delta_{C P}-\delta_{S O}$ versus $f \frac{\ln (f)}{(1-f)}$, respectively, as described in Mariotti et al. (1981). $\delta_{S O}$ is $\delta^{15} \mathrm{~N}$ of initial $\mathrm{NH}_{4}{ }^{+}$and $f$ is the fraction of the initial $\left[\mathrm{NH}_{4}{ }^{+}\right]$remaining in the culture. Uncertainties of $\varepsilon_{R S}$ and $\varepsilon_{C P}$ are expressed as SE of the slope. We used multiple-point estimates because they have lower uncertainty than single-point analyses.

also be underestimated due to concurrent $\mathrm{NH}_{4}{ }^{+}$assimilation, which has a smaller isotope effect. This process would alter observed $\varepsilon_{R S}$ estimates in proportion to the amount of $\mathrm{NH}_{4}{ }^{+}$ assimilated and the isotope effect for $\mathrm{NH}_{4}{ }^{+}$assimilation (4$27 \%$; Hoch et al., 1992). Therefore, we also measured $\delta^{15} \mathrm{~N}$ of the cell biomass at the end of incubation of $N$. viennensis grown on $2 \mathrm{mM} \mathrm{NH}_{4}^{+}$(Figures 1F, 3). Although it is impossible to infer directly the contribution of $\mathrm{N}$ assimilation to $\varepsilon_{R S}$ from just one end-point measurement, we propose that $\mathrm{N}$ assimilation substantially contributed to the decrease of $\varepsilon_{R S}$ relative to $\varepsilon_{C P}$ in our study, as biomass was ${ }^{15} \mathrm{~N}$ enriched by $\sim 10 \%$ compared to initial $\mathrm{NH}_{4}{ }^{+}$. Biomass $\mathrm{N}$ represented $3.1 \%( \pm 0.3 \mathrm{SE})$ of ammonia oxidized by $N$. viennensis grown on $2 \mathrm{mM} \mathrm{NH}_{4}{ }^{+}$. Although dissolved inorganic $\mathrm{N}$ (DIN) concentrations (sum of $\left[\mathrm{NH}_{4}{ }^{+}\right]$and $\left[\mathrm{NO}_{2}^{-}\right]$) were relatively constant over the course of ammonia oxidation, we recovered only $81.9 \%( \pm 1.5 \mathrm{SE})$ of the initial DIN by the end of incubation of $N$. adriaticus, and $94.7 \%( \pm 3.4$ $\mathrm{SE})$ and $90.7 \%( \pm 1.1 \mathrm{SE})$ of $N$. viennensis grown on $1 \mathrm{mM}$ $\mathrm{NH}_{4}{ }^{+}$or $2 \mathrm{mM} \mathrm{NH}_{4}{ }^{+}$, respectively. In $N$. adriaticus cultures, assimilation of $\mathrm{N}$ by contaminant bacteria likely did not contribute substantially to the lower $\varepsilon_{R S}$ relative to $\varepsilon_{C P}$, due to the high enrichment level of the culture (95\%) at the time of the experiment, and the fact that $\varepsilon_{R S}$ of $N$. adriaticus was similar to that of $N$. viennensis in pure culture. In addition, the ${ }^{15} \mathrm{~N}$-enrichment of $N$. viennensis' biomass shows that AMO preferentially, and primarily, reacts on pseudo-periplasmatic $\mathrm{NH}_{3}$, causing ${ }^{15} \mathrm{~N}$-enrichment of the residual ammonia, which is subsequently assimilated into biomass. We thus propose that under substrate replete conditions, the observed isotope effects of $\varepsilon_{R S}$ of $31.9-33.1 \%$ primarily reflect the kinetic isotope effect of the AMO-catalyzed reaction, modified by the $\mathrm{NH}_{4}{ }^{+} / \mathrm{NH}_{3}$ equilibrium isotope effect (19.2\% ; Hermes et al., 1985) and decreased by the contribution of the lower kinetic isotope effect of $\mathrm{NH}_{4}{ }^{+}$assimilation for anabolic purposes (4-27\% ; Hoch et al., 1992). Moreover, it should be noted that some ammonia oxidizers use distinct pathways of $\mathrm{NH}_{4}{ }^{+}$assimilation, even among just AOA, which may contribute to different kinetic isotope effects. For instance, some members of the AOA genus Candidatus Nitrosocosmicus appear to assimilate $\mathrm{NH}_{4}{ }^{+}$via glutamate synthase (GOGAT), whereas all other known AOA use the glutamate dehydrogenase (GDH) pathway (Alves et al., 2019).

Despite these potential isotope fractionation effects on the RS level, a higher $\varepsilon_{C P}$ relative to $\varepsilon_{R S}$ may also result from accumulation of metabolic intermediates, allowing for at least 
TABLE 1 | Compilation of published kinetic isotope effects of AOA and AOB.

\begin{tabular}{|c|c|c|c|c|c|c|c|c|}
\hline \multirow[t]{2}{*}{ Source } & \multirow[t]{2}{*}{ AOA/AOB } & \multirow[t]{2}{*}{ Strain } & \multirow{2}{*}{$\begin{array}{c}\text { Initial }\left[\mathrm{NH}_{4}{ }^{+}\right] \\
(\mathrm{mM})\end{array}$} & \multirow[t]{2}{*}{ Other conditions } & \multicolumn{2}{|c|}{$\varepsilon_{R S}$} & \multicolumn{2}{|c|}{$\varepsilon_{C P}$} \\
\hline & & & & & Mean & SD & Mean & SD \\
\hline \multirow[t]{3}{*}{ This study } & $\mathrm{AOA}$ & Nitrosopumilus adriaticus NF5 & 1 & & 32.1 & 1.0 & 40.1 & 0.7 \\
\hline & $\mathrm{AOA}$ & Nitrososphaera viennensis EN76 & 1 & & 31.9 & 1.2 & 37.7 & 0.8 \\
\hline & $\mathrm{AOA}$ & Nitrososphaera viennensis EN76 & 2 & & 33.1 & 0.7 & 39.0 & 1.2 \\
\hline \multirow[t]{3}{*}{ Santoro and Casciotti (2011) } & $\mathrm{AOA}$ & Marine AOA enrichment CN25† & $0.01-0.075$ & & & & 22 & 5 \\
\hline & & Marine AOA enrichment CN75 & & & & & 21 & 10 \\
\hline & & Marine AOA enrichment CN150 & & & & & 22 & 5 \\
\hline \multirow[t]{2}{*}{ Nishizawa et al. (2016) } & $\mathrm{AOA}$ & Candidatus Nitrosocaldus sp. & 0.2 & & & & 22.0 & 5.0 \\
\hline & & Candidatus Nitrosocaldus sp. & 14 & & & & 24.7 & 2.1 \\
\hline Mariotti et al. (1981) & $\mathrm{AOB}$ & Nitrosomonas europaea & $4.7-25$ & & 34.7 & 2.5 & 31.9 & 6.4 \\
\hline Delwiche and Steyn (1970) & $\mathrm{AOB}$ & Nitrosomonas europaea & & & & & 26.0 & 5.6 \\
\hline \multirow[t]{3}{*}{ Yoshida (1988) } & $\mathrm{AOB}$ & Nitrosomonas europaea & 38 & $\mathrm{pO}_{2}$ low & & & 24.6 & \\
\hline & $\mathrm{AOB}$ & Nitrosomonas europaea & 38 & $\mathrm{pO}_{2}$ medium & & & 29.0 & \\
\hline & $\mathrm{AOB}$ & Nitrosomonas europaea & 38 & $\mathrm{pO}_{2}$ high & & & 32.0 & \\
\hline \multirow[t]{5}{*}{ Casciotti et al. (2003) } & $\mathrm{AOB}$ & Nitrosomonas marina & 2 & & & & 14.2 & 3.6 \\
\hline & & Nitrosomonas sp. C-113a & 2 & & & & 19.1 & 1.2 \\
\hline & & Nitrosospira tenuis & 1 & & & & 24.6 & 1.4 \\
\hline & & Nitrosomonas eutropha & 1 & & & & 32.8 & 1.7 \\
\hline & & Nitrosomonas europaea & 1 & & & & 38.2 & 1.6 \\
\hline \multirow[t]{3}{*}{ Casciotti et al. (2010) } & $\mathrm{AOB}$ & Nitrosomonas sp. C-113a & $0.005-0.05$ & & & & $30-46$ & \\
\hline & $\mathrm{AOB}$ & Nitrosococcus oceani & $0.005-0.05$ & & & & $30-46$ & \\
\hline & $\mathrm{AOB}$ & Nitrosospira briensis & $0.005-0.05$ & & & & $30-46$ & \\
\hline
\end{tabular}

†Currently designated as Candidatus Nitrosopelagicus brevis CN25 (Santoro et al., 2015).

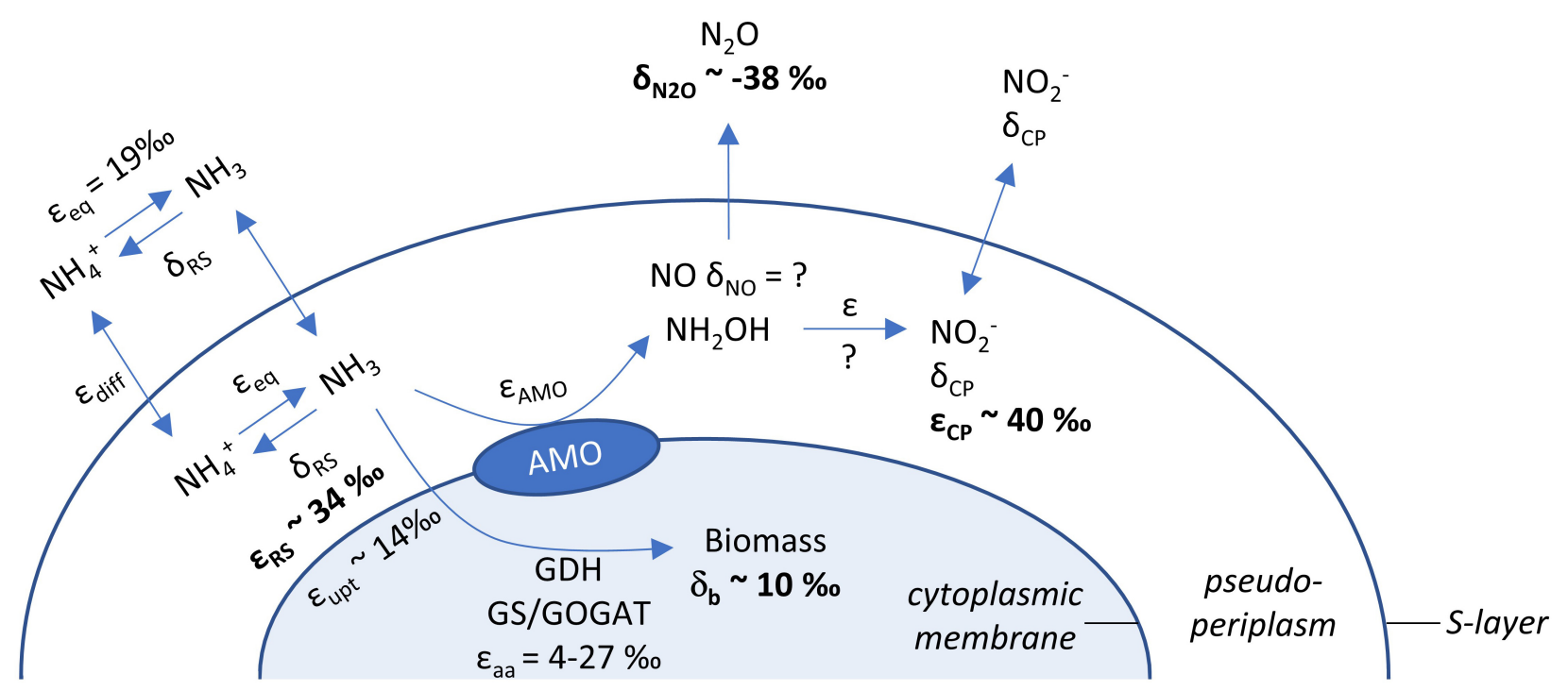

FIGURE 3 | Schematic overview of processes and isotope fractionation effects involved in ammonia oxidation, growth and intermediate formation of the soil AOA $N$. viennensis. $\delta^{15} \mathrm{~N}$ values are given for endpoint measurements of $\mathrm{N}_{2} \mathrm{O}$ and biomass, while average kinetic isotope effects of ammonia oxidation are presented for

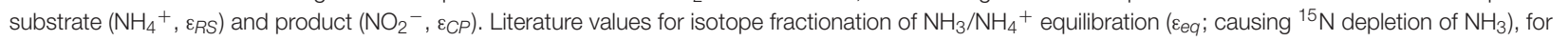
secondary active $\mathrm{NH}_{4}{ }^{+}$uptake $\left(\varepsilon_{u p t}\right)$ and ammonia assimilation $\left(\varepsilon_{a a}\right)$ are presented as well. The identity of the enzyme oxidizing $\mathrm{NH}_{2} \mathrm{OH}$ to $\mathrm{NO}_{2}{ }^{-}$and its inherent isotope fractionation are currently unknown for AOA. 
TABLE 2 | Nitrogen pools for $N$. viennensis culture grown on $2 \mathrm{mM} \mathrm{NH}_{4}{ }^{+}$.

\begin{tabular}{lcccc}
\hline & $\begin{array}{c}\text { N pool } \\
(\boldsymbol{\mu} \mathbf{M})\end{array}$ & $\begin{array}{c}\boldsymbol{\delta}^{\mathbf{1 5}} \mathbf{N} \text { of } \mathbf{N} \\
\text { pool }(\% \mathbf{0})\end{array}$ & $\begin{array}{c}\text { Percent of } \\
\text { missing N pool }\end{array}$ & $\begin{array}{c}\text { Percent of } \\
\text { ammonia } \\
\text { oxidized }\end{array}$ \\
\hline Missing & 204.4 & $-7.6( \pm 5.2)$ & & \\
& $( \pm 25.2)$ & & & $3.1( \pm 0.3)$ \\
Biomass & $38.8( \pm 3.4)$ & $10.1( \pm 0.1)$ & $22.8( \pm 4.1)$ & $0.5( \pm 0.1)$ \\
$\mathrm{N}_{2} \mathrm{O}-\mathrm{N}$ & $6.5( \pm 0.2)$ & $-38.1( \pm 0.3)$ & $3.5( \pm 0.4)$ & \\
Unaccounted & 139.2 & $-18.5( \pm 1.7)$ & $73.7( \pm 4.5)$ & \\
& $( \pm 27.1)$ & & &
\end{tabular}

The missing $\mathrm{N} \mathrm{pool}$ is $\mathrm{N}$ that was not present at $\mathrm{NH}_{4}{ }^{+}$and $\mathrm{NO}_{2}{ }^{-}$at the last sampling time point when biomass and $\mathrm{N}_{2} \mathrm{O}$ was collected for isotope analysis. We used a mass balance approach to calculate $\delta^{15} \mathrm{~N}$ of the missing and unaccounted $\mathrm{N}$ pool. Standard errors are given in parentheses.

a second ${ }^{15} \mathrm{~N}$ isotope fractionation step to be observed. First, accumulation of $\mathrm{NH}_{2} \mathrm{OH}$, or any other intermediate, has not been observed in AOA cells, and the coupled activities of AMO and hydroxylamine oxidoreductase (yet unknown in AOA) are assumed to maintain $\mathrm{NH}_{2} \mathrm{OH}$ at low steady-state concentrations. Therefore, isotope effects associated with $\mathrm{NH}_{2} \mathrm{OH}$ oxidation should have a limited impact on $\delta^{15} \mathrm{NO}_{2}{ }^{-}$. Second, any process that adds an additional isotope fractionation step, either prior, or subsequent, to $\mathrm{NO}_{2}{ }^{-}$formation, such as the production of the gases $\mathrm{NO}$ and $\mathrm{N}_{2} \mathrm{O}$, may result in an under- or overestimation of the kinetic isotope fractionation factor. The effect of $\mathrm{N}_{2} \mathrm{O}$ and $\mathrm{NO}$ production on $\delta^{15} \mathrm{NO}_{2}{ }^{-}$will depend on their formation pathways, and respective isotope effects and by-product yields. In the $N$. viennensis culture grown on $2 \mathrm{mM} \mathrm{NH}_{4}{ }^{+}$, we measured cumulative $\mathrm{N}_{2} \mathrm{O}$ at the end of the incubation, which represented $0.5 \%( \pm 0.01 \mathrm{SE})$ of the $\mathrm{NH}_{4}{ }^{+}$oxidized, or $3.5 \%$ $( \pm 0.4 \mathrm{SE})$ of the "missing" $\mathrm{N}$ pool. $\mathrm{N}_{2} \mathrm{O}$ yields of AOA are generally low. For example, N. viennensis has been shown to produce $\mathrm{N}_{2} \mathrm{O}$ at rates of about $0.1 \%$ of those of ammonia oxidation when grown on $1 \mathrm{mM} \mathrm{NH}{ }_{4}+/ \mathrm{NH}_{3}$ (Stieglmeier et al., 2014b), whereas the marine AOA N. maritimus SCM1 produces even less (0.002-0.03\%; Löscher et al., 2012). Here, the cumulative $\mathrm{N}_{2} \mathrm{O}$ of the $N$. viennensis culture had a $\delta^{15} \mathrm{~N}$ of $-38.1 \%$ ( $\pm 0.3 \mathrm{SE}$ ) (Figures $1 \mathbf{F}, 3$ ), which was more ${ }^{15} \mathrm{~N}$ depleted than previously observed for AOA enrichment cultures. AOA have been shown to produce $\mathrm{N}_{2} \mathrm{O}$ with $\delta^{15} \mathrm{~N}$ signatures ranging between -35 and $-13 \%$ in soil enrichment cultures and $-9 \%$ in marine enrichment cultures (Santoro et al., 2011; Jung et al., 2014), while $\mathrm{N}_{2} \mathrm{O}$ produced by $\mathrm{AOB}$ tends to have lower $\delta^{15} \mathrm{~N}$, ranging between $-66 \%$ (Nitrosomonas europaea; Yoshida, 1988) and $-10 \%$ (Nitrosomonas marina; Frame and Casciotti, 2010). Furthermore, by-products that are more ${ }^{15} \mathrm{~N}$ depleted than the main product of ammonia oxidation (i.e., $\mathrm{NO}_{2}{ }^{-}$) would decrease the apparent kinetic isotope effect of AMO $\left(\varepsilon_{C P}\right)$, instead of increasing it. Using an isotopic mass balance approach, we calculated that the missing $\mathrm{N}$ pool (i.e., the $\mathrm{NH}_{4}{ }^{+}$taken up which was not oxidized to $\mathrm{NO}_{2}{ }^{-}$), would need to have a $\delta^{15} \mathrm{~N}$ of $-18.5 \%$ ( $\left.\pm 1.7 \mathrm{SE}\right)$ in order to account for the difference in isotope fractionation between $\varepsilon_{R S}$ and $\varepsilon_{C P}$ (Table 2). Therefore, the $\delta^{15} \mathrm{~N}_{2} \mathrm{O}$ signature of $-38.1 \%$ cannot explain the observed large isotope fractionation based on $\delta^{15} \mathrm{NO}_{2}{ }^{-}$, since the $\mathrm{N}_{2} \mathrm{O}$ produced would need to be a larger contributor to the "missing" $\mathrm{N}$ pool, as well as to be ${ }^{15} \mathrm{~N}$-enriched relative to $\mathrm{NO}_{2}^{-}$.

Nitric oxide is an important intermediate in the ammonia oxidation pathway, particularly in that of AOA. Unlike in $\mathrm{AOB}, \mathrm{NO}$ is a necessary co-reactant for the oxidation of $\mathrm{NH}_{2} \mathrm{OH}$ to $\mathrm{NO}_{2}^{-}$in AOA, despite being produced in relatively small amounts (Kozlowski et al., 2016). Although the $\delta^{15} \mathrm{~N}$ signature of NO produced by AOA has not yet been determined, Yoshida (1988) found that NO produced during nitrification by $N$. europaea had a $\delta^{15} \mathrm{~N}$ between 0 and $+20 \%$. The production of such ${ }^{15} \mathrm{~N}$-enriched $\mathrm{NO}$ could significantly contribute to the observed overestimation of $\varepsilon_{C P}$ in AOA.

\section{CONCLUSION}

In conclusion, our results show that, under non-limiting substrate conditions, the $\varepsilon_{A M O}$ of two phylogenetically and ecologically distinct AOA strains was $31.9-33.1 \%$ based on $\delta^{15} \mathrm{NH}_{4}{ }^{+}$, whereas the more commonly estimated $\varepsilon_{A M O}$ based on $\delta^{15} \mathrm{NO}_{2}{ }^{-}$was higher (37.7-40.1\%0). Thus, $\mathrm{NH}_{4}{ }^{+}$assimilation, but not $\mathrm{N}_{2} \mathrm{O}$ production, significantly affected the isotope fractionation factor of AMO estimated for N. viennensis (Figure 3). Although the potential role of NO in this context remains to be tested, isotopic analysis of this molecule is difficult and therefore future measurements of $\varepsilon_{A M O}$ may rely on coupled estimates from $\delta^{15} \mathrm{NH}_{4}{ }^{+}$and $\delta^{15} \mathrm{NO}_{2}{ }^{-}$.

\section{DATA AVAILABILITY STATEMENT}

The raw data supporting the conclusion of this article have been deposited at DRYAD (doi: 10.5061/dryad.0gb5mkkz1).

\section{AUTHOR CONTRIBUTIONS}

WW designed the study. MMo, RA, BB, MMe, MS, LJ, SR, and MW performed the experiments. MMo, RA, BB, MS, and LJ analyzed the data. $\mathrm{GH}$ and $\mathrm{CS}$ provided the resources and strains. MMo, RA, and WW wrote the manuscript with contributions from all co-authors.

\section{FUNDING}

This study was funded by the Austrian Science Fund (FWF; project P28037-B22). Open access funding was provided by University of Vienna.

\section{ACKNOWLEDGMENTS}

We thank the students of the course "Stable Isotopes in Ecology" of the years 2012-2014 at the University of Vienna, who contributed to the sample analyses and discussion of the data. 


\section{REFERENCES}

Alves, R. J. E., Kerou, M., Zappe, A., Bittner, R., Abby, S. S., Schmidt, H., et al. (2019). Ammonia oxidation by the arctic terrestrial thaumarchaeote Ca. Nitrosocosmicus arcticus is stimulated by increasing temperatures. Front. Microbiol. 10:1571. doi: 10.3389/fmicb.2019.01571

Ariz, I., Boeckstaens, M., Gouveia, C., Martins, A. P., Sanz-Luque, E., Fernández, E., et al. (2018). Nitrogen isotope signature evidences ammonium deprotonation as a common transport mechanism for the AMT-Mep-Rh protein superfamily. Sci. Adv. 4:eaar3599. doi: 10.1126/sciadv.aar3599

Arp, D. J., and Stein, L. Y. (2003). Metabolism of inorganic N compounds by ammonia-oxidizing bacteria. Crit. Rev. Biochem. Mol. Biol. 38, 471-495. doi: 10.1080/10409230390267446

Bayer, B., Pelikan, C., Bittner, M. J., Reinthaler, T., Könneke, M., Herndl, G. J., et al. (2019). Proteomic response of three marine ammonia-oxidizing archaea to hydrogen peroxide and their metabolic interactions with a heterotrophic alphaproteobacterium. mSystems 4:e0181-19. doi: 10.1128/mSystems.0018119

Bayer, B., Vojvoda, J., Offre, P., Alves, R. J. E., Elisabeth, N. H., Garcia, J. A. L., et al. (2016). Physiological and genomic characterization of two novel marine thaumarchaeal strains indicates niche differentiation. ISME J. 10, 1051-1063. doi: 10.1038/ismej.2015.200

Buchwald, C., and Casciotti, K. L. (2013). Isotopic ratios of nitrite as tracers of the sources and age of oceanic nitrite. Nat. Geosci. 6, 308-313. doi: 10.1038/ ngeo 1745

Caranto, J. D., and Lancaster, K. M. (2017). Nitric oxide is an obligate bacterial nitrification intermediate produced by hydroxylamine oxidoreductase. Proc. Natl. Acad. Sci. U.S.A. 114, 8217-8222. doi: 10.1073/pnas.1704504114

Carini, P., Dupont, C., and Santoro, A. E. (2017). Correlated expression of archaeal ammonia oxidation machinery across disparate environmental and culture conditions. BioRxiv [Preprint]. doi: 10.1101/175141

Casciotti, K. L. (2016). Nitrogen and oxygen isotopic studies of the marine nitrogen cycle. Ann. Rev. Mar. Sci. 8, 379-407. doi: 10.1146/annurev-marine-010213135052

Casciotti, K. L., and Buchwald, C. (2012). Insights on the marine microbial nitrogen cycle from isotopic approaches to nitrification. Front. Microbiol. 3:356. doi: 10.3389/fmicb.2012.00356

Casciotti, K. L., McIlvin, M., and Buchwald, C. (2010). Oxygen isotopic exchange and fractionation during bacterial ammonia oxidation. Limnol. Oceanogr. 55, 753-762. doi: 10.4319/lo.2010.55.2.0753

Casciotti, K. L., Sigman, D. M., and Ward, B. B. (2003). Linking diversity and stable isotope fractionation in ammonia-oxidizing bacteria. Geomicrobiol. J. 20, 335-353. doi: 10.1080/01490450303895

Daims, H., Lebedeva, E. V., Pjevac, P., Han, P., Herbold, C., Albertsen, M., et al. (2015). Complete nitrification by Nitrospira bacteria. Nature 528:504. doi: 10.1038 /nature 16461

Delwiche, C. C., and Steyn, P. L. (1970). Nitrogen isotope fractionation in soils and microbial reactions. Environ. Sci. Technol. 4, 929-935. doi: 10.1021/ es60046a004

Frame, C. H., and Casciotti, K. L. (2010). Biogeochemical controls and isotopic signatures of nitrous oxide production by a marine ammonia-oxidizing bacterium. Biogeosciences 7, 2695-2709. doi: 10.5194/bg-7-2695-2010

Goyal, S. S., Rains, D. W., and Huffaker, R. C. (1988). Determination of ammonium ion by fluorometry or spectrophotometry after on-line derivatization with o-phthalaldehyde. Anal. Chem. 60, 175-179. doi: 10.1021/ac00153a016

Hermes, J. D., Weiss, P. M., and Cleland, W. W. (1985). Use of nitrogen15 and deuterium isotope effects to determine the chemical mechanism of phenylalanine ammonia-lyase. Biochemistry 24, 2959-2967. doi: 10.1021/ bi00333a023

Hoch, M. P., Fogel, M. L., and Kirchman, D. L. (1992). Isotope fractionation associated with ammonium uptake by a marine bacterium. Limnol. Oceanogr. 37, 1447-1459. doi: 10.4319/lo.1992.37.7.1447

Hood-Nowotny, R., Umana, N. H.-N., Inselbacher, E., Oswald- Lachouani, P., and Wanek, W. (2010). Alternative methods for measuring inorganic, organic, and total dissolved nitrogen in soil. Soil Sci. Soc. Am. J. 74:1018. doi: 10.2136/ sssaj2009.0389

Houlton, B. Z., and Bai, E. (2009). Imprint of denitrifying bacteria on the global terrestrial biosphere. Proc. Natl. Acad. Sci. U.S.A. 106, 21713-21716. doi: 10. 1073/pnas.0912111106
Jung, M.-Y., Well, R., Min, D., Giesemann, A., Park, S.-J., Kim, J.-G., et al. (2014). Isotopic signatures of $\mathrm{N} 2 \mathrm{O}$ produced by ammonia-oxidizing archaea from soils. ISME J. 8, 1115-1125. doi: 10.1038/ismej.2013.205

Kerou, M., Offre, P., Valledor, L., Abby, S. S., Melcher, M., Nagler, M., et al. (2016). Proteomics and comparative genomics of Nitrososphaera viennensis reveal the core genome and adaptations of archaeal ammonia oxidizers. Proc. Natl. Acad. Sci. U.S.A. 113, E7937-E7946. doi: 10.1073/pnas.1601212113

Kits, K. D., Sedlacek, C. J., Lebedeva, E. V., Han, P., Bulaev, A., Pjevac, P., et al. (2017). Kinetic analysis of a complete nitrifier reveals an oligotrophic lifestyle. Nature 549:269. doi: 10.1038/nature23679

Kozlowski, J. A., Stieglmeier, M., Schleper, C., Klotz, M. G., and Stein, L. Y. (2016). Pathways and key intermediates required for obligate aerobic ammoniadependent chemolithotrophy in bacteria and Thaumarchaeota. ISME J. 10, 1836-1845. doi: 10.1038/ismej.2016.2

Lachouani, P., Frank, A. H., and Wanek, W. (2010). A suite of sensitive chemical methods to determine the $\delta 15 \mathrm{~N}$ of ammonium, nitrate and total dissolved $\mathrm{N}$ in soil extracts. Rapid Commun. Mass Spectrom. 24, 3615-3623. doi: 10.1002/rcm. 4798

Li, P.-N., Herrmann, J., Tolar, B. B., Poitevin, F., Ramdasi, R., Bargar, J. R., et al. (2018). Nutrient transport suggests an evolutionary basis for charged archaeal surface layer proteins. ISME J. 12, 2389-2402. doi: 10.1038/s41396-018-0191-0

Löscher, C. R., Kock, A., Koenneke, M., LaRoche, J., Bange, H. W., and Schmitz, R. A. (2012). Production of oceanic nitrous oxide by ammonia-oxidizing archaea. Biogeosciences 9, 2419-2429. doi: 10.5194/bg-9-2419-2012

Mariotti, A., Germon, J. C., Hubert, P., Kaiser, P., Letolle, R., Tardieux, A., et al. (1981). Experimental determination of nitrogen kinetic isotope fractionation: some principles; illustration for the denitrification and nitrification processes. Plant Soil 62, 413-430. doi: 10.1007/bf02374138

Martens-Habbena, W., Berube, P. M., Urakawa, H., José, R., and Stahl, D. A. (2009). Ammonia oxidation kinetics determine niche separation of nitrifying Archaea and Bacteria. Nature 461:976. doi: 10.1038/nature08465

Nishizawa, M., Sakai, S., Konno, U., Nakahara, N., Takaki, Y., Saito, Y., et al. (2016). Nitrogen and oxygen isotope effects of ammonia oxidation by thermophilic Thaumarchaeota from a geothermal water stream. Appl. Environ. Microbiol. 82, 4492-4504. doi: 10.1128/aem.00250-16

Offre, P., Kerou, M., Spang, A., and Schleper, C. (2014). Variability of the transporter gene complement in ammonia-oxidizing archaea. Trends Microbiol. 22, 665-675. doi: 10.1016/j.tim.2014.07.007

Prosser, J. I, Hink, L., Gubry-Rangin, C., and Nicol, G. W. (2019). Nitrous oxide production by ammonia oxidisers: physiological diversity, niche differentiation and potential mitigation strategies. Glob. Chang. Biol. 26, 103-118. doi: 10. $1111 /$ gcb. 14877

Prosser, J. I., and Nicol, G. W. (2012). Archaeal and bacterial ammonia-oxidisers in soil: the quest for niche specialisation and differentiation. Trends Microbiol. 20, 523-531. doi: 10.1016/J.TIM.2012.08.001

R Development Core Team (2012). R: A Language and Environment for Statistical Computing. Vienna: R Foundation for Statistical Computing.

Santoro, A. E., Buchwald, C., McIlvin, M. R., and Casciotti, K. L. (2011). Isotopic signature of $\mathrm{N} 2 \mathrm{O}$ produced by marine ammonia-oxidizing archaea. Science 333 , 1282-1285. doi: 10.1126/science.1208239

Santoro, A. E., and Casciotti, K. L. (2011). Enrichment and characterization of ammonia-oxidizing archaea from the open ocean: phylogeny, physiology and stable isotope fractionation. ISME J. 5:1796. doi: 10.1038/ismej.2011.58

Santoro, A. E., Dupont, C. L., Richter, R. A., Craig, M. T., Carini, P., McIlvin, M. R., et al. (2015). Genomic and proteomic characterization of "Candidatus Nitrosopelagicus brevis": an ammonia-oxidizing archaeon from the open ocean. Proc. Natl. Acad. Sci. U.S.A. 112, 1173-1178. doi: 10.1073/pnas.1416223112

Shen, T., Stieglmeier, M., Dai, J., Urich, T., and Schleper, C. (2013). Responses of the terrestrial ammonia-oxidizing archaeon $\mathrm{Ca}$. Nitrososphaera viennensis and the ammonia-oxidizing bacterium Nitrosospira multiformis to nitrification inhibitors. FEMS Microbiol. Lett. 344, 121-129. doi: 10.1111/1574-6968.12164

Sigman, D. M., and Casciotti, K. L. (2001). "Nitrogen isotopes in the ocean," in Encyclopedia of Ocean Sciences, ed. J. H. Steele (Cambridge, MA: Academic Press), 1884-1894. doi: 10.1006/rwos.2001.0172

Simon, J., and Klotz, M. G. (2013). Diversity and evolution of bioenergetic systems involved in microbial nitrogen compound transformations. Biochim. Biophys. Acta Bioenerget. 1827, 114-135. doi: 10.1016/j.bbabio.2012.07.005

Sørensen, P., and Jensen, E. S. (1991). Sequential diffusion of ammonium and nitrate from soil extracts to a polytetrafluoroethylene trap for $15 \mathrm{~N}$ 
determination. Anal. Chim. Acta 252, 201-203. doi: 10.1016/0003-2670(91) 87215-s

Stieglmeier, M., Klingl, A., Alves, R. J. E., Rittmann, S. K.-M. R., Melcher, M., Leisch, N., et al. (2014a). Nitrososphaera viennensis gen. nov., sp. nov., an aerobic and mesophilic, ammonia-oxidizing archaeon from soil and a member of the archaeal phylum Thaumarchaeota. Int. J. Syst. Evol. Microbiol. 64, 2738-2752. doi: 10.1099/ijs.0.063172-0

Stieglmeier, M., Mooshammer, M., Kitzler, B., Wanek, W., ZechmeisterBoltenstern, S., Richter, A., et al. (2014b). Aerobic nitrous oxide production through $\mathrm{N}$-nitrosating hybrid formation in ammonia-oxidizing archaea. ISME J. 8, 1135-1146. doi: 10.1038/ismej.2013.220

Tourna, M., Stieglmeier, M., Spang, A., Könneke, M., Schintlmeister, A., Urich, T., et al. (2011). Nitrososphaera viennensis, an ammonia oxidizing archaeon from soil. Proc. Natl. Acad. Sci. U.S.A. 108, 8420-8425. doi: 10.1073/pnas.101348 8108

van Kessel, M. A. H. J., Speth, D. R., Albertsen, M., Nielsen, P. H., den Camp, H. J. M. O., Kartal, B., et al. (2015). Complete nitrification by a single microorganism. Nature 528, 555-559. doi: 10.1038/nature16459

Vitousek, P. M., Menge, D. N. L., Reed, S. C., and Cleveland, C. C. (2013). Biological nitrogen fixation: rates, patterns and ecological controls in terrestrial ecosystems. Philos. Trans. R. Soc. B Biol. Sci. 368:20130119. doi: 10.1098/rstb. 2013.0119

Walker, C. B., De La Torre, J. R., Klotz, M. G., Urakawa, H., Pinel, N., Arp, D. J., et al. (2010). Nitrosopumilus maritimus genome reveals unique mechanisms for nitrification and autotrophy in globally distributed marine crenarchaea.
Proc. Natl. Acad. Sci. U.S.A. 107, 8818-8823. doi: 10.1073/pnas.091353 3107

Yoshida, N. (1988). 15N-depleted $\mathrm{N} 2 \mathrm{O}$ as a product of nitrification. Nature 335:528. doi: 10.1038/335528a0

Yoshida, N., and Toyoda, S. (2000). Constraining the atmospheric N2O budget from intramolecular site preference in N2O isotopomers. Nature 405, 330-334. doi: $10.1038 / 35012558$

Conflict of Interest: The authors declare that the research was conducted in the absence of any commercial or financial relationships that could be construed as a potential conflict of interest.

Citation: Mooshammer M, Alves RJE, Bayer B, Melcher M, Stieglmeier M, Jochum L, Rittmann SK-MR, Watzka M, Schleper C, Herndl GJ and Wanek W (2020) Nitrogen Isotope Fractionation During Archaeal Ammonia Oxidation: Coupled Estimates From Measurements of Residual Ammonium and Accumulated Nitrite. Front. Microbiol. 11:1710. doi: 10.3389/fmicb.2020.01710

Copyright (C) 2020 Mooshammer, Alves, Bayer, Melcher, Stieglmeier, Jochum, Rittmann, Watzka, Schleper, Herndl and Wanek. This is an open-access article distributed under the terms of the Creative Commons Attribution License (CC BY). The use, distribution or reproduction in other forums is permitted, provided the original author(s) and the copyright owner(s) are credited and that the original publication in this journal is cited, in accordance with accepted academic practice. No use, distribution or reproduction is permitted which does not comply with these terms. 